SMOKING

\title{
Efficacy of bupropion in the indigenous Maori population in New Zealand
}

\author{
S Holt, C Timu-Parata, S Ryder-Lewis, M Weatherall, R Beasley
}

Thorax 2005;60:120-123. doi: 10.1136/thx.2004.030239

See end of article for authors' affiliations

.....

Correspondence to: Dr S Holt, P3 Research Bowen Hospital, Churchill

Drive, Crofton Downs Wellington, New Zealand; shaun@p3research.co.nz

Received 17 June 2004 Accepted 3 October 2004

\begin{abstract}
Background: Smoking rates are high in indigenous populations and contribute to their poor health. In New Zealand the indigenous Maori population has a high rate of smoking, with around $50 \%$ of adults being smokers compared with $20 \%$ of the adult European population. A study was undertaken to determine whether bupropion is effective in the treatment of smoking cessation in the indigenous Maori population in New Zealand.

Methods: A randomised, placebo controlled, double blind, parallel group study was performed in 134 Maori smokers aged 16-70 years who smoked more than 10 cigarettes per day. The main outcome measures were continued abstinence from smoking at 3 and 12 months.

Results: At each time point continued abstinence was better for the subjects allocated to bupropion, with a risk ratio for abstinence over all time points of $2.44(95 \% \mathrm{Cl} 1.22$ to 4.88$)$. The rates of continued abstinence in the bupropion and placebo groups at 3 months were $44.3 \%$ and $17.4 \%$, respectively, with a risk ratio of 2.54 (95\% $\mathrm{Cl} 1.30$ to 5.00). The corresponding figures at 12 months were $21.6 \%$ and $10.9 \%$, respectively, with a risk ratio of 1.99 (95\% $\mathrm{Cl} 0.79$ to 5.00$)$.

Conclusion: Bupropion is an effective treatment for smoking cessation in the indigenous Maori population in New Zealand.
\end{abstract}

S moking is a major public health issue worldwide and is a risk factor for many diseases, particularly lung cancer chronic obstructive airways disease, coronary heart disease and cerebrovascular disease. Smoking tobacco is the leading cause of preventable death in the world, causing more than 4 million deaths per year. ${ }^{1}$ It has been estimated that smoking will kill 10 million people per year worldwide by the year $2025 .^{2}$

The World Health Organization (WHO) launched the Decade of the World's Indigenous Peoples initiative in 1994. There are around 5000 indigenous groups worldwide, in every continent, with a total population of about 200 million or $4 \%$ of the world population. ${ }^{3}$ Indigenous populations have different patterns of health, often with an unacceptably poorer health status than the non-indigenous population. ${ }^{4}$ For example, the difference in life expectancy between the indigenous population and the non-indigenous population has been found to be 4-21 years in several countries. ${ }^{4}$ Proposed reasons for these disparities include genetic vulnerability, socioeconomic disadvantage, and political oppression. ${ }^{5}$ A large proportion of the chronic diseases which contribute to the difference in life expectancy is preventable.

Smoking rates tend to be high in indigenous populations and contribute significantly to their burden of poor health. For example, in Australia 56\% of indigenous men and $48 \%$ of women smoke compared with $27 \%$ and $20 \%$ of the whole population. ${ }^{6}$ In New Zealand $40-50 \%$ of Maori adolescents and adults are smokers compared with around $20 \%$ of the European population. ${ }^{78}$ One study has estimated that $31 \%$ of deaths among the Maori population in the period 1989-1993 were due to smoking. ${ }^{9}$

Despite many smokers wanting to quit, only $2-6 \%$ manage to stop smoking each year. ${ }^{10}{ }^{11}$ Smoking has been shown not to be simply a habit but is a complex physiological addiction. Smoking cessation techniques are primarily behavioural (such as counselling) and/or pharmacological. Until recently pharmacological treatments were based on delivery of nicotine via a patch, gum, inhaler, or nasal spray. ${ }^{12}{ }^{13}$
However, bupropion (Zyban) is a pharmacological treatment for smoking cessation which is available in tablet form and does not deliver nicotine. ${ }^{13-17}$ Bupropion, which acts on dopaminergic pathways, was originally used as an antidepressant but it was discovered in initial clinical studies that smokers were able to quit smoking after taking bupropion for depression. ${ }^{18}$ Studies have since demonstrated its efficacy and safety resulting in a near doubling of the smoking cessation rate, ${ }^{14-17}$ which is higher than that due to nicotine replacement therapy. ${ }^{19}$ However, no studies have assessed the efficacy and safety of bupropion for smoking cessation in an indigenous population. The aim of this study was to determine the effectiveness of bupropion for smoking cessation in Maori, the indigenous population in New Zealand.

\section{METHODS \\ Design}

A randomised, placebo controlled, double blind, parallel group, single centre study was undertaken in the Wellington and Kapiti regions in New Zealand, comparing the smoking cessation rate achieved with a 7 week course of bupropion and counselling with that achieved with placebo and counselling. Participants were followed up for 12 months after start of treatment.

\section{Participants}

The study participants were self-recruited from advertising in local media and actively recruited from Maori health networks. Regular meetings were held during which the details of the study were presented, including the inclusion and exclusion criteria. Suitable participants were then invited to attend a screening visit. The inclusion criteria were: selfidentified as Maori; 16-70 years of age; smoking $\geqslant 10$ cigarettes per day on average over the previous year; wanting to stop smoking; women of child bearing potential with a negative pregnancy test at visit 1 and a reliable method of contraception. The exclusion criteria were: history of epilepsy, 


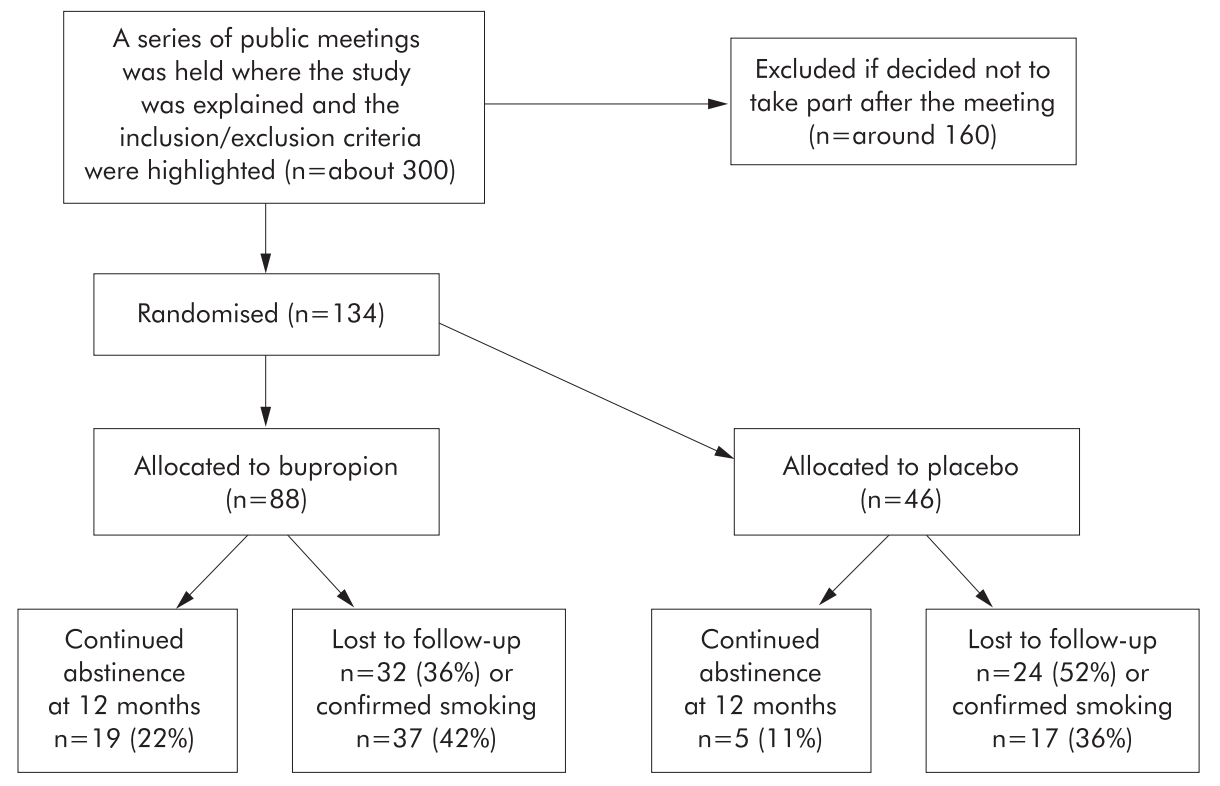

Figure 1 CONSORT flow of subjects through study.

febrile convulsions, CNS tumour, head injury, cerebrovascular disease; anorexia or bulimia; significant cardiovascular disease including unstable angina, a myocardial infarction in the previous 3 months, arrhythmias, uncontrolled hypertension; other severe illness such as renal, hepatic or neurological disease; pregnant or lactating; history of alcohol or drug abuse; unwilling to stop smoking marijuana during the trial. The flow of subjects through the study is shown in fig 1 .

\section{Treatments and randomisation}

At the first visit participants who fulfilled the entry criteria were randomised using a computer generated code to either bupropion $150 \mathrm{mg}$ once daily for 3 days, then $150 \mathrm{mg}$ twice daily for 7 weeks, or identical placebo. Both treatment groups also received smoking cessation counselling. There was a 2:1 randomisation (that is, two participants were allocated to the bupropion group for each participant allocated to the placebo group) because it was recognised that recruitment was likely to be enhanced by subjects having an increased probability of allocation to the active treatment. Neither the study team nor the participant was aware of which treatment had been allocated until the end of the 12 month study period.

\section{Study procedures}

At the first visit one blinded medication pack was dispensed and a target quit date (TQD) set for 7-14 days after the visit. Other assessments consisted of baseline demographic information, Fagerstrom score, weight, and an exhaled carbon monoxide (CO) reading (Smoke Check, Micro Medical Ltd, Rochester, UK). Participants then received a motivational telephone call 1 day before and 3 days after the TQD. Clinic visits were scheduled for 3 weeks, 7 weeks, 3 months, 6 months, 9 months, and 12 months after the TQD to assess smoking status, with measurement of exhaled $\mathrm{CO}$ and adverse events, and to provide counselling.

Counselling topics were tailored to the needs of the individual participant and included support and advice on motivation to quit, identification of smoking triggers, diet, exercise and the role of family, friends and work colleagues.

In the event of premature discontinuation, all attempts were made to collect any unused medication, to ascertain the reason for discontinuation, and to follow up the smoking status of the participant for the 12 month study duration.

\section{Outcome variables}

The primary outcome variables were continued abstinence from smoking at 3 and 12 months. Secondary outcome variables were continued abstinence from smoking at other time points, including a model based analysis, and adverse events.

Continuous abstinence was defined as no cigarettes from the TQD and had to be confirmed with a negative exhaled CO measured by the Smoke Check device at each of the clinic visits. It should be emphasised that only rates of continuous abstinence proven biochemically were assessed.

Participants who were lost to follow up were categorised as smokers. These participants did not attend follow up sessions and did not return telephone calls. All were assumed to be smoking and often this was confirmed by family members or friends.

Table 1 Demographic data of study groups

\begin{tabular}{|c|c|c|c|c|}
\hline Variable & Bupropion & Placebo & $\begin{array}{l}\text { Difference } \\
(95 \% \mathrm{CI})\end{array}$ & $\begin{array}{l}\text { p value for } \\
\text { difference }\end{array}$ \\
\hline Age (years)* & $41.7(9.2)$ & $38.0(11.1)$ & $3.7(0.1$ to 7.3$)$ & 0.04 \\
\hline Fagerstrom index* & $5.8(2.2)$ & $5.3(2.0)$ & $0.5(-0.3$ to 1.3$)$ & 0.22 \\
\hline $\begin{array}{l}\text { Weight at initial } \\
\text { assessment }(\mathrm{kg})^{*}\end{array}$ & $85.4(18.9)$ & $80.2(16.8)$ & $5.2(-1.3$ to 11.8$)$ & 0.12 \\
\hline $\begin{array}{l}\text { Women/total, } \\
\text { n/N (\%) }\end{array}$ & $61 / 88$ (69.3) & $35 / 46(76.1)$ & $-6.8(-22.4$ to 8.9$)$ & 0.41 \\
\hline
\end{tabular}


Table 2 Analysis of non-smoking rates by measurement time without adjustment for repeated measurements

\begin{tabular}{llll}
\hline $\begin{array}{l}\text { Measurement } \\
\text { time }\end{array}$ & $\begin{array}{l}\text { Buproprion non-smoker } \\
\mathbf{N}(\% \text { of } 88)\end{array}$ & $\begin{array}{l}\text { Placebo non-smoker } \\
\mathbf{N}(\% \text { of } 46)\end{array}$ & $\begin{array}{l}\text { Risk difference expressed as } \\
\text { proportion } \times 100(95 \% ~ C l)\end{array}$ \\
\hline 3 days & $71(80.7)$ & $37(80.4)$ & $0.25(-13.9$ to 14.4$)$ \\
3 weeks & $62(70.5)$ & $22(47.8)$ & $22.6(5.3$ to 40.0$)$ \\
7 weeks & $48(54.6)$ & $18(39.1)$ & $15.4(-2.0$ to 32.9$)$ \\
13 weeks & $39(44.3)$ & $8(17.4)$ & $26.9(11.8$ to 42.0$)$ \\
26 weeks & $26(29.6)$ & $5(10.9)$ & $18.7(5.6$ to 31.8$)$ \\
39 weeks & $24(27.3)$ & $5(10.9)$ & $16.4(3.5$ to 29.3$)$ \\
52 weeks & $19(21.6)$ & $5(10.9)$ & $10.7(-1.7$ to 23.2$)$ \\
\hline
\end{tabular}

\section{Statistical methods}

For the primary analysis, comparison of smoking status was by the normal approximation to the binomial distribution and expressed as both a difference in proportions and risk ratio for the primary outcomes. A secondary analysis used a generalised estimating equation approach modelling the logit of the proportion of subjects who were non-smokers by treatment status and the time of observation using an exchangeable correlation structure to model the repeated measures. Exploratory analysis with a general additive model suggested a non-linear relationship between the logit of the probability of abstinence and time. A model with a break point at 26 weeks was also fitted to the data. The proportions of subjects with a particular adverse effect were calculated using as the denominator the total number of subjects allocated to the particular treatment arm. Confidence intervals for proportions were calculated as exact confidence intervals. Where a zero cell count was observed, risk ratios were not calculated. SAS version 8.2 (SAS Institute, Cary, NC, USA) was used.

It was calculated that, to detect a difference in proportions in one group of 0.3 and in a second group of 0.1 at an $\alpha$ value of 0.05 with an $80 \%$ power in a trial with equal allocation to treatments, 62 subjects were needed in each group. With 2:1 allocation it was calculated that 47 subjects were needed in one group and 94 in the other. ${ }^{20}$

As this study exclusively involved Maori participants, extensive consultation with the Maori Health Unit of Capital and Coast Health was undertaken. A Maori research nurse was employed to undertake this study. The study was approved by the Wellington ethics committee.

\section{RESULTS}

\section{Demographic data}

One hundred and thirty four participants were randomised to the study and their demographic details are summarised in

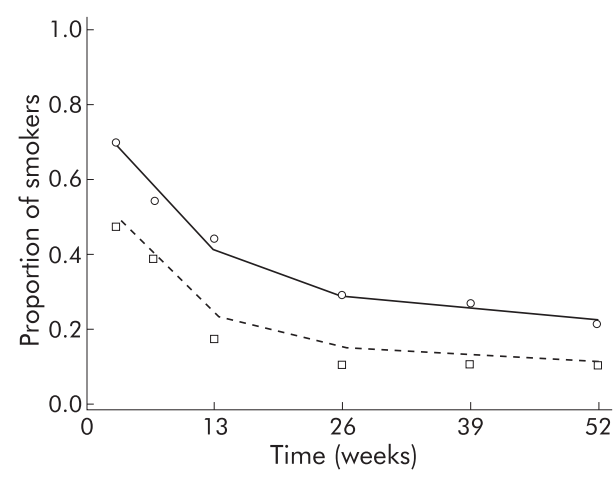

Figure 2 Plot of fitted and actual probabilities for continued abstinence for active treatment (open circles) and placebo (open squares) using a break point at week 26 . The solid line indicates predicted on bupropion and the broken line indicates predicted on placebo. table 1 . More women than men were recruited, reflecting the higher smoking rates in Maori women. The bupropion group was slightly younger on average than the placebo group. It was not possible to recruit the projected 141 participants due to a lack of eligible subjects within the communities studied.

\section{Efficacy measures}

The rates of continued abstinence at various time points are shown in table 2. At 3 months the rates of continued abstinence in the bupropion and placebo groups were $44.3 \%$ and $17.4 \%$, respectively, with a risk ratio of 2.54 (95\% CI 1.30 to 5.00$)$. At 12 months the corresponding figures were $21.6 \%$ and $10.9 \%$, respectively, with a risk ratio of 1.99 (95\% CI 0.79 to 5.00$)$.

For the model based approach with a break point in the abstinence-time slope at 26 weeks, the risk ratio for abstinence favoured the bupropion group (2.44 (95\% CI 1.22 to 4.88 )). Figure 2 shows the fitted and raw probabilities for the repeated measures model.

\section{Safety}

Most side effects were mild and self-limiting. Participants taking bupropion were more likely to have insomnia $(26 \% \mathrm{v}$ $9 \%$; risk ratio 3.0 (95\% CI 1.1 to 8.2$)$ ). Three participants who were taking bupropion did not complete the course of treatment because of a rash.

\section{DISCUSSION}

Smoking rates in indigenous populations around the world are often very high and, to our knowledge, this is the first trial to assess the use of bupropion for smoking cessation in such a group. We found that bupropion and counselling led to a 12 month biochemically proven continuous abstinence rate of $21.6 \%$ compared with a rate of $10.9 \%$ for placebo and counselling. At each time point abstinence was better for the subjects allocated to bupropion, and a model based secondary analysis found a risk ratio of 2.44 (95\% CI 1.22 to 4.88 ) in favour of bupropion over all time points. Bupropion was also safe and generally well tolerated, although three subjects did not complete treatment with bupropion due to a rash.

Our findings are comparable with other major studies which have assessed bupropion as an aid to stopping smoking in general populations of smokers ${ }^{14-1921}$ and those with cardiovascular disease ${ }^{22}$ and COPD. ${ }^{23}$ The Cochrane Library Systematic Review ${ }^{24}$ which undertook a metaanalysis of 10 placebo controlled trials of bupropion for initial cessation found a risk ratio for 12 month abstinence of 1.97 (95\% CI 1.67 to 2.34 ), which is similar to the risk ratio for continued abstinence at 12 months of 1.99 (95\% CI 0.79 to 5.00$)$ observed in our study.

An important consideration with our study is that a number of the participants could not be followed up for the whole 12 month study duration. We assumed that these participants had started smoking and this was usually confirmed by a third party. We have therefore carried out a "worst case" scenario-namely, that all subjects lost to 
follow up were smokers. This may have underestimated the continuous abstinence rates.

There are three other important issues relevant to the interpretation of the study. Firstly, our findings cannot necessarily be generalised to other indigenous groups or ethnic minorities. However, it is worthy of note that the findings are comparable to a similar study by Ahluwalia et al ${ }^{21}$ in African American smokers in which a $21 \%$ quit rate was observed after 6 months with bupropion compared with $13.7 \%$ with placebo. In this study bupropion treatment also resulted in a greater reduction in depression symptoms than placebo and, after controlling for continuous abstinence, those taking bupropion gained less weight than placebo. Secondly, the smokers in our study were a self-selected highly motivated group which may limit the applicability of the findings to all smokers. However, such a group highly motivated to quit probably represents the preferable group for pharmacological intervention. Thirdly, it is possible that some participants may have been classified as abstinent yet smoked intermittently between clinic visits, but this is unlikely as the participants knew that they were being tested for continued smoking and, if it did occur, it would have been expected to affect both groups similarly.

Another feature of our study was that about $40 \%$ of participants were able to quit smoking for 3 months with bupropion and counselling but many had relapsed by 12 months. This pattern has been consistently observed with studies of pharmacological methods to achieve smoking cessation. ${ }^{14} 1519$ It may be that future research should focus on the group who are able to quit for a significant period of time, perhaps by assessing the role of additional or longer courses of bupropion and/or nicotine replacement therapy. However, studies of the effect of bupropion on prevention of relapse after initial cessation have to date been disappointing. ${ }^{25}$

One issue which was not examined in our study but which is of clinical relevance is the comparison between bupropion and the standard pharmacological approach of nicotine replacement therapy. This has been investigated in one published study ${ }^{19}$ in which bupropion was found to be significantly more effective than nicotine patch (odds ratio $2.07,95 \%$ CI 1.22 to 3.53 ). This therapeutic issue requires further study, as does the comparison between bupropion and other antidepressants such as nortriptyline. ${ }^{24}$

Finally, it is important that, in establishing smoking cessation interventions based on the results of this study, similar programmes are put in place. The smoking cessation programme was based on the principles of cultural safety, reducing barriers and encouraging access through community based clinics with key involvement of Maori health providers. ${ }^{26}$ It cannot be assumed that similar outcomes would be achieved through the establishment of programmes involving different services such as hospital based clinics.

In summary, this study has found that a community based programme using bupropion treatment combined with counselling is a safe and effective method of smoking cessation in the Maori population. Its efficacy is similar in this indigenous population to that in the general population of smokers and those with cardiovascular disease and COPD.

\section{ACKNOWLEDGEMENTS}

The authors acknowledge the valuable contributions of Dale Wilson Tama Tua and Colleen Wineera of the Maori Health Unit, Capital and Coast Health, Wellington and Avrille Holt, P3 Research.

\section{Authors' affiliations}

S Holt, C Timu-Parata, S Ryder-Lewis, P3 Research, Wellington, New Zealand

M Weatherall, Wellington School of Medicine and Health Sciences, Wellington, New Zealand

R Beasley, Medical Research Institute of New Zealand, Wellington, New Zealand and University of Southampton, Southampton, UK

This study was supported by a research grant from GlaxoSmithKline to P3 Research.

Conflict of interest: P3 Research, the Wellington School of Medicine and Health Sciences, and the Medical Research Institute of New Zealand have all received research grants from GlaxoSmithKline and Novartis. $\mathrm{SH}$ and $\mathrm{RB}$ have received fees for consulting and reimbursement for attending symposia from GlaxoSmithKline and Novartis.

$\mathrm{SH}$ and RB designed the study and wrote the manuscript with help from the other authors; SH coordinated the study, collected data with CT-P and SR-L; MW undertook the data analysis. SH will act as guarantor.

\section{REFERENCES}

1 World Health Organization. World health report. Geneva: World Health Organization, 1999

2 Peto R, Lopez A. The future of worldwide smoking patterns. In: Koop CE, Pearson C, Schwarz R, eds. Critical issues in global health. New York: JosseyBass, 2000:154-61.

3 Committee on Indigenous Health. The Geneva declaration on the health and survival of indigenous peoples, WHO/HSD/00.1. Geneva: World Health Organization, 1999.

4 Ring I, Brown N. The health status of indigenous peoples and others. BMJ 2003;327:404-5

5 Durie MH. The health of indigenous peoples. BMJ 2003;326:510-1.

6 Anon. Cigarette smoking among indigenous Australians, Australian Bureau of Statistics 4701.0, 1994.

7 Borman B, Wilson N, Mailing C. Socio-demographic characteristics of New Zealand smokers: results from 1996 census. NZ Med J 1999;1 12:460-3.

8 Klemp P, Robertson MC, Stansfield S, et al. Factors associated with smoking and the reasons for stopping in Maori and Europeans. NZ Med J 1998;111:148-51.

9 Lambe J. Smoking kills 31\% of Maori. NZ Med J 1998;111:27.

10 Kane KY, Ellis MR. Bupropion or patch for smoking cessation? J Fam Prac 1999;48:419.

11 Galgali G, Beaglehole R, Scragg R, et al. Potential for prevention of premature death and disease in New Zealand. NZ Med J 1997:1 10:7-10.

12 Molyneux $A$. ABC of smoking cessation: nicotine replacement therapy. BMJ 2004;328:454-6.

13 Dale CL, Hurt RD, Hays JT. Drug therapy to aid in smoking cessation. Postgrad Med 1998;104:75-84.

14 Richmond R, Zwar N. Review of bupropion for smoking cessation. Drug Alcohol Rev 2003;22:203-20.

15 Holm KJ, Spencer CM. Bupropion. A review of its use in the management of smoking cessation. Drugs 2000;59:1007-24.

16 Roddy $\mathrm{E}$. $\mathrm{ABC}$ of smoking cessation: bupropion and other non-nicotine pharmacotherapies. BMJ 2004;328:509-11.

17 Hurt RD, Sachs DPL, Glover ED, et al. A comparison of sustained-release bupropion and placebo for smoking cessation. N Engl J Med 1997;337: 1195-202.

18 Rennard SI, Daughton DM. Smoking cessation. Chest 2000;117:360-4S

19 Jorenby DE, Leischow SJ, Nides MA, et al. A controlled trial of sustained release bupropion, a nicotine patch, or both for smoking cessation. N Engl J Med 1999;340:685-91.

20 Campbell MJ, Julious SA, Altman DG, et al. Estimating sample sizes for binary, ordered categorical, and continuous outcomes in two group comparisons. BMJ 1995;311:1145-8.

21 Ahluwalia JS, Harris KJ, Catley D, et al. Sustained-release bupropion for smoking cessation in African Americans. JAMA 2002;288:468-74.

22 Tonstad S, Farsang C, Klaene G, et al. Bupropion SR for smoking cessation in smokers with cardiovascular disease: a multicentre, randomised study. Eur Heart J 2003;24:946-55.

23 Tashkin D, Kanner R, Bailey W, et al. Smoking cessation in patients with chronic obstructive pulmonary disease: a double-blind, placebo-controlled, randomised trial. Lancet 2001;357:1571-5.

24 Hughes JR, Stead LF, Lancaster T. Antidepressants for smoking cessation. Cochrane Tobacco Addiction Group. Cochrane Database of Systematic Reviews, 1:2004

25 Hays JT, Hurt RD, Figotti NA, et al. Sustained-release bupropion for pharmacologic relapse prevention after smoking cessation. A randomized, controlled trial. Ann Intern Med 2001;135:423-33.

26 McPherson KM, Harwood M, McNaughton HK. Ethnicity, equity and quality: lessons from New Zealand. BMJ 2003;327:443-4. 